\title{
COMPLETE MONOTONICITY OF SOME FUNCTIONS INVOLVING $k$-DIGAMMA FUNCTION WITH APPLICATION
}

\author{
LI YIN*, LI-GUO HUANG AND XIU-Li LIN
}

Abstract. We present several complete monotonicity properties involving $k$-digamma function with single parameter. These established results provide a $k$-generalization for the known results obtained by Burić and Elezović in [5]. Finally, we give an application to the generalized Nielsen's $\beta$-function and pose two open problems.

Mathematics subject classification (2010): Primary 33B15; Secondary 26A48, 26 A51. Keywords and phrases: $k$-digamma function, complete monotonicity, inequalities.

\section{REFERENCES}

[1] M. Abramowitz, I. Stegun, eds., Handbook of mathematical functions with formulas, graphs and mathematical tables, National Bureau of Standards, Dover, New York, 1965.

[2] H. AlZER, Sharp inequalities for the digamma and polygamma functions, Forum Math., 16 (2004), $181-221$

[3] N. BATIR, On some properties of digamma and polygamma functions, J. Math. Anal. Appl., 3281 (2014), 452-465.

[4] N. BATIR, Some new inqualities for gamma and polygamma functions, J. Inequal. Pure Appl. Math., 64 (2005), Art. 103.

[5] T. BuRić AND N. Elezović, Some completely monotonic functions related to psi function, Math. Inequal. Appl., 143 (2011).

[6] S. N. ChiU And CH. -C. YIn, On the Complete Monotonicity of the Compound Geometric Convolution with Applications to Risk Theory, Scandinavian Actuarial Journal, 2014 (2), 2014, 116-124.

[7] R. Díaz And E. PARIguan, On hypergeometric functions and Pochhammer $k$-symbol, Divulg. Mat. 152 (2007), 179-192.

[8] H. Dong AND CH.-C. YIN, Complete monotonicity of the probability of ruin and DE Finetti's dividend problem, J. Syst. Sci Complex, 25 (1), 2012, 178-185.

[9] B.-N. GuO AND F. QI, Some properties of the psi and polygamma functions, Hacet. J. Math. Stat., 39, 2 (2010), 219-231.

[10] B.-N. GUO AND F. QI, Two new proofs of the complete monotonicity of a function involving the psi function, Bull. Korean Math. Soc., 47, 1 (2010), 103-111.

[11] B.-N. GUO, F. QI AND H. M. SRIVASTAVA, Some uniqueness results for the non-trivially complete monotonicity of a class of functions involving the polygamma and related functions, Integral Transforms Spec. Funct., 21, 11 (2010), 849-858.

[12] B.-N. GuO, J.-L. ZHAO, F. QI, A completely monotonic function involving divided dirrerences of the tri- and tetra-gamma functions, Math. Slovaca, 63, 3 (2013), 469-478.

[13] L. MATEJIV̌CKA, Notes on three conjectures involving the digamma and generalized digamma functions, J. Inequal. Appl. (2018) 2018:342.

[14] K. Nantomah, Convexity properties and inequalities concerning the ( $p, k)$-gamma functions, Commun. Fac. Sci. Univ. Ank. Sér. A1. Math. Stat., 66, 2 (2017), 130-140.

[15] K. Nantomah, F. Merovei And S. NASIRU, Some monotonic properties and inequalities for the $(p, q)$-gamma function, Kragujevac J. Math., 42, 2 (2018), 287-297.

[16] K. Nantomah, E. Prempeh And S. B. Twum, On a $(p, k)$-analogue of the gamma function and some associated inequalities, Moroccan J. Pure Appl. Anal., 2, 2 (2016), 79-90. 
[17] N. Nielsen, Handbuch der Theorie der Gammafunktion, First Edition, Leipzig: B. G. Teubner, 1906.

[18] F. QI AND C.-P. Chen, Some completely monotonic and polygamma functions, J. Aust. Math. Soc., 80 (2006), 81-88.

[19] F. QI AND B.-N. GuO, A class of completely monotonic functions involving divided differences of the psi and tri-gamma functions and some applications, J. Korean Math. Soc., 48, 3 (2011), 655-667.

[20] F. QI, S.-L. GUO AND B.-N. GUO, Completely monotonicity of some functions involving polygamma functions, J. Comput. Appl. Math., 233, (2010), 2149-2160.

[21] F. QI AND B.-N. GuO, Completely monotonic functions involving divided differences of the di- and tri-gamma functions and some applications, Commun. Pure Appl. Anal., 8, 6 (2009), 1975-1989.

[22] F. QI AND B.-N. GuO, Necessary and sufficient conditons for functions involving the tri- and tetragamma functions to be completely monotonic, Adv. Appl. Math., 44, 1 (2010), 71-83.

[23] R. L. Schilling, R. Song, And Z. VondrăceK, Bernstein Functions, de Gruyter Studies in Mathematics 37, De Gruyter, Berlin, Germany, 2010.

[24] L. YIN, Complete monotonicity of a function involving the $(p ; k)$-digamma function, Int. J. Open Problems Compt. Math., 11, No: 2, (2018), 103-108.

[25] L. Yin, L.-G. HuAng, X.-L. Lin AND Y.-L. WANG, Monotonicity, concavity, and inequalities related to the generalized digamma function, Advances in Difference Equations (2018) 2018:246.

[26] L. Yin, L.-G. HUAng, ZH.-M. Song AND X.-K. Dou, Some monotonicity properties and inequalities for the generalized digamma and polygamma functions, J. Inequal. Appl. (2018) 2018:249. 